\title{
Level Controller by Computer
}

\author{
Carmona, $\mathbf{J}^{1}$. Sanchez, $\mathbf{G}^{2}$, Rodriguez, $\mathrm{K}^{3}$ \\ ${ }^{1}$ Technological University of Tlaxcala, Industrial Maintenance Area,Road to Él Carmen Xalpatlahuaya S/N. Huamantla, Tlaxcala. \\ ${ }^{2}$ Apizaco Institute of Technology, Dept. Electrical and Electronics, Apizaco-Tzompantepec Road, Apizaco, Tlaxcala. \\ ${ }^{3}$ Autonomous University of Tlaxcala, DeptLanguage, Ocotlán Road,corner. Morelos S/N Tlaxcala, Tlax.
}

\begin{abstract}
A control option is presented by a computer to storage medium capacity tanks, recording physical variables in real time to create a predictive and preventive maintenance.
\end{abstract}

Keywords: LINX, Graphic Language, Power Amplifier, Data Acquisition.

\section{Introduction}

There are some system controllers on the market which do not allow the properly register of the information of the variables on its components. Therefore, this project presents a low cost proposal which not only monitors the storage, but also generates a record of the physical variables to create a predictive and preventive maintenance.

\section{Approach}

In the north part of the state of Tlaxcala there are some towns which count with grain storages. There remains the importance to monitor the conditions in which their structures and equipment are. It is important to mention that it is quite impossible to know the certain amount of product they contain because they are raised tanks and they are not easy to reach, creating a potential risk to the people who wants to know the amount of grains they contain.

\section{Objective}

Create acontroller device which allows record in chronological order the physical variables of the storage system due to monitor the facilities and anticipate further damages in the equipment.

\section{Theoretical Framework}

In this section the scientific basis in which this project is based on, is presented.

\subsection{Introduction}

It is necessary to employ data cards in order to develop the platforms which operate in real time because they enable the interaction between the physical environment and the software. In this project a low-cost interface was applied. Therefore the manufacture was affordable.

\subsection{Programing Software}

The software used to develop the control interface was the one from National Instruments LabVIEW.(Fig. 1)

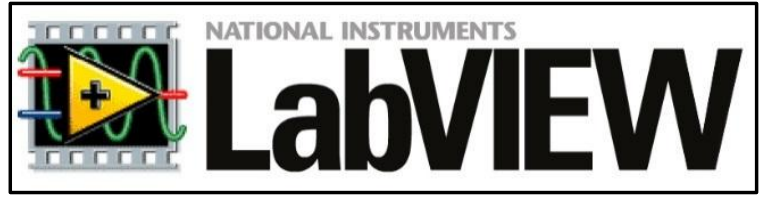

Figure1: Labview logo

LabVIEW(Laboratory Virtual Instrumentation Engineering Workbench) is a platform and graphical software for the design of systems. Recommended for system test, control and design hardware and software, simulated or real. The language it uses is called language $\mathrm{G}$ for graphic.

This program was created by National Instruments (1976) for MAC machines. It was launched for first time in 1986. Nowadays it is available for other platforms, such as Windows, UNIX, MAC y GNU/Linux. The second to last version is the one from 2013. It can be used for the RF last generation instrument firmware design with an open code. Moreover the 2014 version is a demo available for students and professionals. It can be downloaded from the National Instruments website [1].

\subsection{Power Electronics}

For this project it is proposed a circuit with a cut- saturation transistor (Fig. 2). It is insulated electrically through an optoisolator in order to prevent damages in the control phase.

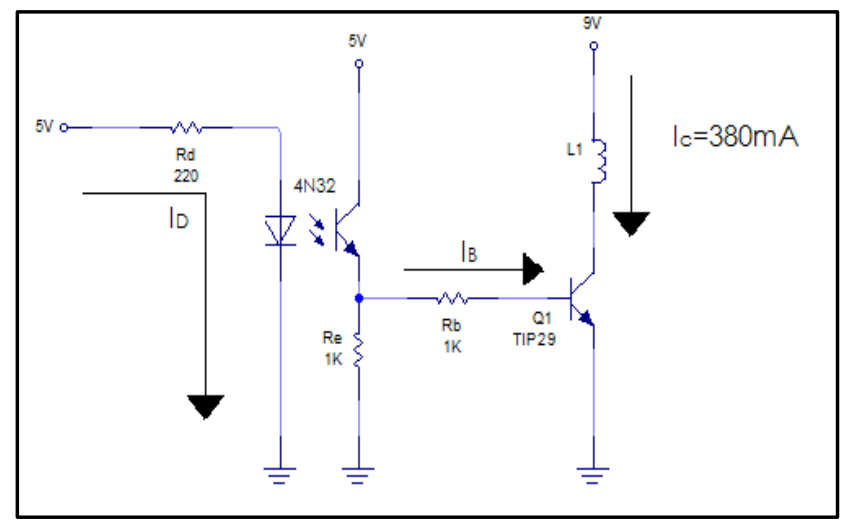

Figure2: Power phase circuit

Making the circuit calculation [2], we get: 


\section{International Journal of Science and Research (IJSR) \\ ISSN (Online): 2319-7064}

Index Copernicus Value (2013): 6.14 | Impact Factor (2014): 5.611

\subsubsection{Transistor Assigment}

According to the current used by the pumps and the operation voltage of this equipment, it can be assigned a TIP29A transistor with the next characteristics:

Chart 1:TIP29A Technical Information

\begin{tabular}{|c|c|}
\hline \multicolumn{2}{|c|}{ TIP 29A } \\
\hline Manifoldcurrent $\left(\mathrm{I}_{\mathrm{c}}\right)$ & $\mathrm{I}_{\mathrm{C}}=1 \mathrm{Amp}$. \\
\hline Manifold-transmitter exit voltage $\left(\mathrm{V}_{\mathrm{CEO}}\right)$ & $\mathrm{V}_{\mathrm{CEO}}=60 \mathrm{~V}$ \\
\hline Unionresistance $\left(\mathrm{R}_{\theta \mathrm{JC}}\right)$ & $\mathrm{R}_{\Theta i c}=4.17^{\circ} \mathrm{C} / \mathrm{W}$ \\
\hline $\mathrm{h}_{\mathrm{fe}}(\beta)$ & $\beta=75$ \\
\hline Total power $\left(\mathrm{P}_{\mathrm{T}}\right)$ & $P_{T}=30 \mathrm{~W}$ \\
\hline
\end{tabular}

\subsubsection{Emisor}

$$
\begin{aligned}
R_{D} & =\frac{V_{i}}{I_{D}} \\
R_{D} & =\frac{5 v}{20 m A} \\
R_{D} & =250 \Omega
\end{aligned}
$$

It does not exist a resistance value of $250 \Omega$ commercially, that is why it is recommended to[3]select a next lower resistance just not to affect the circuit. It was selected a $220 \Omega$ resistance which produces a22mA current. According to the opto-isolator fact sheet, it allows a continuing current of $80 \mathrm{~mA}$. Therefore it does not exist any problem when placing the resistance.

The power of $R_{D}$ will be:

$$
\begin{gathered}
P_{D}=\frac{V^{2}}{R} \\
P_{D}=\frac{5^{2}}{220} \\
P_{D}=113 \mathrm{~mW}
\end{gathered}
$$

\subsubsection{Receiver}

It is need to generate a $5.06 \mathrm{~mA}$ current so $\mathrm{R}_{\mathrm{E}}$ :

$$
\begin{gathered}
R_{E}=\frac{V_{i}}{I_{B}} \\
R_{E}=\frac{5 v}{5.06 m A} \\
R_{E}=988.14 \Omega \\
R_{E}=1 \mathrm{~K} \Omega
\end{gathered}
$$

$\mathrm{R}_{\mathrm{E}}$ power

$$
\begin{gathered}
P=\frac{V^{2}}{R} \\
P=\frac{5^{2}}{1000} \\
P=25 m W
\end{gathered}
$$

\subsubsection{Transistor.}

For the $\mathrm{R}_{\mathrm{B}}$ transistor selection, $\mathrm{I}_{\mathrm{B}}$ is calculated first

$$
\begin{gathered}
I_{B}=\frac{I_{B}}{\beta} \\
I_{B}=\frac{380 \mathrm{~mA}}{75} \\
I_{B}=5.06 \mathrm{~mA} \\
R_{B}=\frac{V_{i}}{I_{B}} \\
R_{B}=\frac{5 \mathrm{v}}{5.06 \mathrm{~mA}} \\
R_{B}=988.14 \Omega \\
R_{B}=1 \mathrm{~K} \Omega
\end{gathered}
$$

The power of $R_{B}$ is:

$$
\begin{gathered}
P=I^{2} R \\
P=\left(5.06^{2}\right) * 1000 \\
P=25 \mathrm{~mW}
\end{gathered}
$$

\subsubsection{Power heatsink.}

The total power dissipation of circuit is: [4]

$$
\begin{gathered}
P_{C}=V_{C} * I_{C} \\
P_{C}=(12) *(380 \mathrm{~mA}) \\
P_{C}=4.56 \mathrm{~W}
\end{gathered}
$$

We know that $R_{\theta j c}$ is $4.17^{\circ} \mathrm{C} / \mathrm{w}$ to $12 \mathrm{~V}$

$$
T_{J}=125^{\circ} \mathrm{C}
$$

The power will to dissipate be $4.56 \mathrm{~W}$ inambient temperature of $40^{\circ} \mathrm{C}$. Thus the thermal resistance of the power heatsink will be:

$$
\begin{aligned}
& R_{t h}=\frac{T_{J}-T_{a}}{P} \\
= & \frac{125^{\circ} \mathrm{C}-40^{\circ} \mathrm{C}}{4.56 \mathrm{w}} . \\
= & 18.64^{\circ} \mathrm{C} / \mathrm{w} .
\end{aligned}
$$

Commercially, it could be the 2905.7 model of the brand DISIPA S.C.P. (Fig. 3) with a thermal resistance of $35^{\circ} \mathrm{C} / \mathrm{W}$.

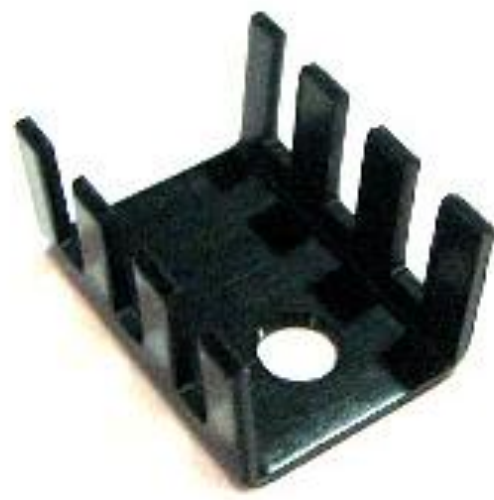

Figure 3: Heat sink Mod. 2905.7

With this model we can generate the PCB (Fig. 4) with measures of $69 \mathrm{~mm} * 65 \mathrm{~mm}$. It counts with boreholes of $4 \mathrm{~mm}$ in order to hold it to the base.

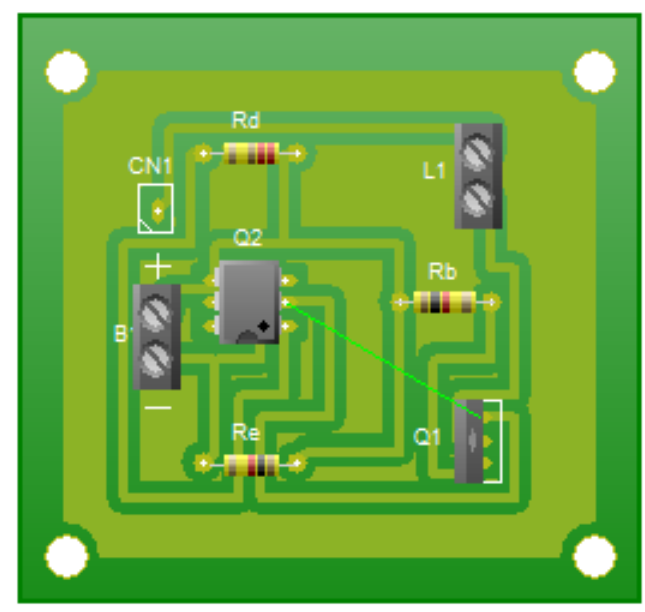

Figure 4: $\mathrm{PCB}$ power phase

It can be notice that there is enough space for the power heatsink to be collocated in the transistor, as well as the terminals. The integrated circuit, which works as opto- 


\section{International Journal of Science and Research (IJSR) \\ ISSN (Online): 2319-7064 \\ Index Copernicus Value (2013): 6.14 | Impact Factor (2014): 5.611}

isolator, has enough space in order to do not affect any component in case of a flaw.

\section{Methodology}

In this section the construction and development sequence of the trial equipment is shown, which is a prototype of a real analysis system.

\subsection{Introduction.}

It is presented the design and construction of the prototype for trials, the AID configuration and the calculation procedure for the correct operation on the control interface.

\subsection{AID firware}

In order to get the information and be able to analyze the physic variables, an ARDUINO ONE card is used (Fig. 5)

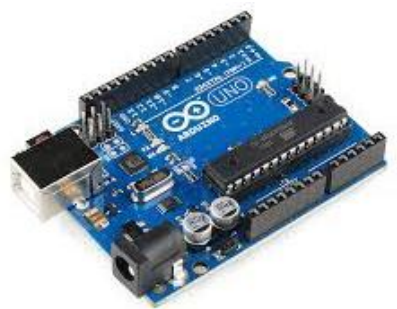

Figure 5: Acquisition of information card

To be able to use this AID (Acquisition of information card), it has to be downloaded a firmware from the LabVIEW software, which can be acquired in the VI Package Manager, from the same software.

It is important to mention that it is necessary to have previously installed the Tool NI Visa, which allows external peripherals.

Having this done, it can be downloaded the firmware from the AID, by the menu Tools/LabVIEW Hacker/ LINX, selecting the microcontroller and the communication port.

\subsection{Programming and calculation of the deposit}

The development of the control platform is done by the software LabVIEW with the design pallets it counts with. (Fig.6).

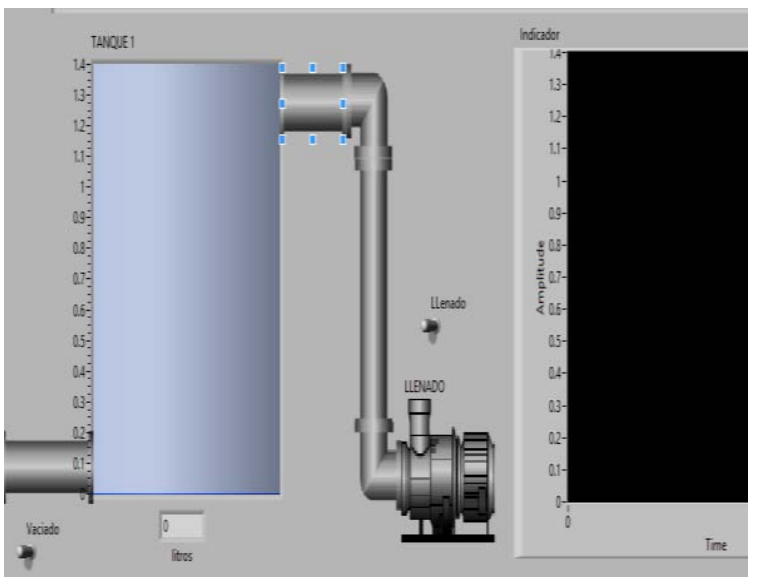

Figure 6: control interface
The calculation of the deposit to control is done analytically due to the ultrasound gage, which performs the measurement (Fig. 7), just measures the distance from its base to the reflective surface.

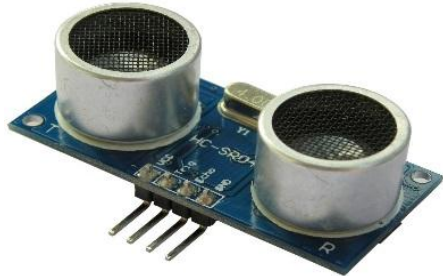

Figure 7: Ultrasound gage

It is necessary to determine the area of the bottom of the container tank. By being a cylinder the equation will be:

$$
A=\pi * r^{2}
$$

Having the date, we can determine the volume with the device. It will give us the high measurement by following the following volume equation:

$$
V=A * h
$$

The equation will calculate in centimeters, but for this project we need to know the volume in liters. Therefore a conversion has to be done.

$$
1 \text { cubic meter }=1000 \text { liters }
$$

The issue here is that the sensor will indicate the high missing to fill the tank and not the high of the liquid entering or going out from the container tank. For this reason the total high has to be considered to get the high of the liquid entering (Fig. 8).

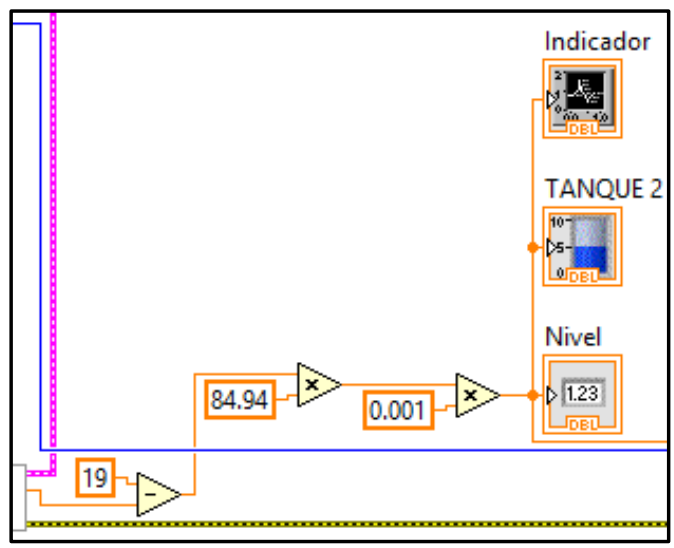

Figure 8: Depositcalculation.

\subsection{Prototype Development}

The prototype development was made with commercial parts, reason why the production was not expensive and it allows a real simulation of the interface.

This Project permits to develop competences in the team members such as information treatment, autonomy and personal initiative.

The production stages consist on the deposit ensemble and the placement of centrifuge bombs in the front side. While in the back side, a space is assigned for the circuit, which allows controlling the project.(Fig. 9) 


\section{International Journal of Science and Research (IJSR) \\ ISSN (Online): 2319-7064}

Index Copernicus Value (2013): 6.14 | Impact Factor (2014): 5.611

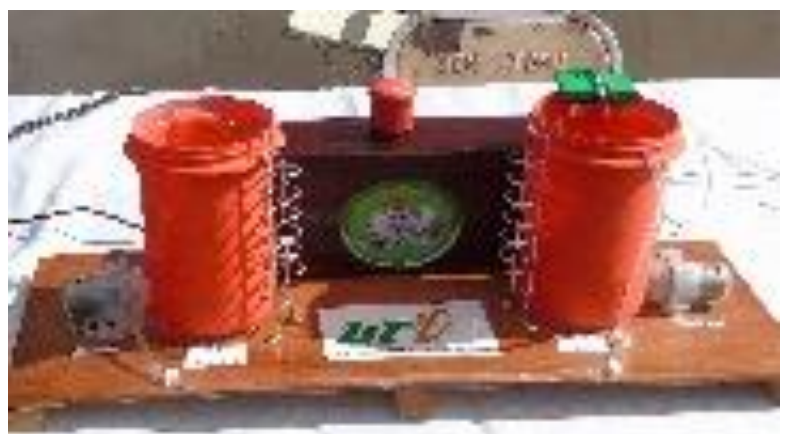

Figure 9: Project finished

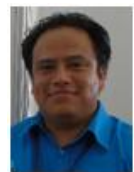

Jonny Carmonagraduated from the Technological Institute of Apizaco in 2010 with a bachelor's degree in Electronic Engineering, specialty in automation and instrumentation. He worked as an electronic engineer in MIF company, developing electronic projects for the steel industry from 2010 to 2015 . Since to 2013 , he has been working as a teacher in the Technological University of Tlaxcala in the industrial maintenance career.

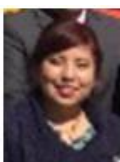

Ketzalzin Elsie RodriguezPortillagraduated from the Autonomous University of Tlaxcala in 2012, specialty in Applied Modern Languages. Since 2013, she has been teaching English in the Technological University of Tlaxcala.

There is a mechanic block mechanism (stoppage), which is possible to activate in order to protect the system from a possible situation.

\section{Conclusion}

This Project shows the way we can acquire physical magnitudes information in order to be able to manipulate them for the benefit of a process or system. Recording the variables permit to make critical decisions about the equipment, which is constantly working and recording, all this for the purpose of preventing resources loss and stoppages, which most of the time produces expenses.

\section{References}

[1] J. R. Lajara Vizcaino y J. P. Sebastiá, LabVIEW Entorno gráfico de programación, Barcelona: Marcombo, 2011.

[2] R. L. Boylestad, Electronica Teoria de Circuitos, Mexico: Printice Hall, 2000.

[3] A. Hermosa Donate, Electronica Aplicada, Barcelona: Marcombo, 2011.

[4] T. L. Floyd, Dispositivos Electronicos, Mexico: Prentice Hall, 2008.

[5] M. N.O. Sadiku , Elementos de Electromagnetismo, México, D.F.: Oxford University Press México, S.A, 2003.

[6] T. Zhang, Aprendiendo C en 24 horas, México: Pearson Educacion, 2001.

[7] J. Oxer y H. Blemings, Practical Arduino Cool Projects for Open Source Hardware, USA: Apress, 2009.

[8] T. Bress, Effective LabVIEW Programming, National Technology and Science Press, 2013.

[9] R. Bitter, T. Mohiuddin y M. Nawrocki, LabVIEW Advanced Programming Techniques, USA: CRC Press, 2007.

[10]N. Ertugrul, LabVIEW for Electric Circuits, Machines, Drives and Laboratories, USA: Prentice Hall.

\section{Author Profile}

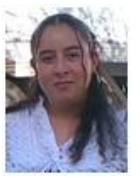

Guillermina Sanchezgraduated from the Technological Institute of Apizaco in 2010 with a bachelor's degree in Electronic Engineering, specialty in automation and instrumentation. She has been in charge of the laboratories in the department of electronic engineering since 2011. 